\title{
Macrocephaly, epilepsy, autism, dysmorphic features, and mental retardation in two sisters: a new autosomal recessive syndrome?
}

\author{
Karen Helene Ørstavik, Petter Strømme, Johan Ek, Ansgar Torvik, Ola H Skjeldal
}

Department of

Medical Genetics,

Ulleval Hospital, Box

1036 Blindern, 0315

Oslo, Norway

K H Ørstavik

Centre for Child

Neurology and

Habilitation,

Department of

Paediatrics, National

Hospital, Oslo, Norway

P Strømme

O H Skjeldal

\section{Department of}

Paediatrics, Buskerud

Central Hospital,

Drammen, Norway

J Ek

Division of

Neuropathology,

Department of

Pathology, Ullevå

Hospital, Oslo, Norway

A Torvik

Correspondence to:

Dr Ørstavik.

Received 7 February 1997

Revised version accepted for publication 3 April 1997

\begin{abstract}
We report two sisters with macrocephaly, epilepsy, and severe mental retardation. The first child was a 14 year old girl born at term after a normal pregnancy, with birth weight $3600 \mathrm{~g}$ and occipitofrontal circumference (OFC) $36 \mathrm{~cm}$ (75th centile). Her head size increased markedly during the first six months of life, and was later stable at $2-3 \mathrm{~cm}$ above the 97.5 th centile. Her development was characterised by psychomotor delay, epilepsy, and autistic features. Her face appeared mildly dysmorphic with a large forehead, short philtrum, and bushy eyebrows. Her younger sister was also born at term with birth weight $2600 \mathrm{~g}$ and OFC $34 \mathrm{~cm}$ (25th centile). She also developed postnatal macrocephaly with OFC $2 \mathrm{~cm}$ above the 97.5th centile and the same mild dysmorphic facial features as her sister. Her development was also characterised by psychomotor delay, autistic features, and epilepsy. In addition, she suffered from coeliac disease. She died unexpectedly at the age of 5 years, probably from an epileptic attack. Necropsy confirmed megalencephaly but no other pathological changes were found. The clinical features in these two sisters do not fit with any known syndrome and may represent a previously unrecognised autosomal recessive disorder.

( Med Genet 1997;34:849-851)
\end{abstract}

Keywords: macrocephaly; autistic; mental retardation; autosomal recessive

Although microcephaly is more commonly associated with mental retardation than macrocephaly, the London Dysmorphology Database $^{1}$ has included 105 mental retardation-macrocephaly syndromes. We report here two mentally retarded sisters with macrocephaly, epilepsy, autistic features, and mild craniofacial dysmorphism. The observations do not fit with any previously reported syndrome.

\section{Case reports}

PATIENT 1

She was a 14 year old girl born at term after a normal pregnancy. Birth weight was $3600 \mathrm{~g}$, length $52 \mathrm{~cm}$, and OFC $36 \mathrm{~cm}$ (75th centile). Head size increased rapidly after birth, but after 6 months the OFC remained stable 2-3 $\mathrm{cm}$ above the 97.5 th centile.

Developmental milestones were delayed; she sat at 12 months, walked at 28 months, and did not learn to speak coherently. Since the age of 4 she has had epileptic seizures characterised by series of eye blinking. From the age of 11 she developed generalised complex seizures with nocturnal apnoea, myoclonus, gurgling sounds, and increased salivation. EEG showed slow background rhythm, epileptogenic spikewave activity in both temporal lobes, and outbursts of rhythmic 1-2/second delta wave activity in the right temporoparietal region accompanied by staring spells.

When last examined at the age of 14 her OFC was $60 \mathrm{~cm}(3 \mathrm{~cm}>97.5$ th centile), while height and weight were at the 50th and 97.5th centiles, respectively. She had mild dysmorphic features with a high and broad forehead, deep set eyes, short philtrum, thick hair, bushy eyebrows, and a hairy upper lip (fig 1). Her mood was flat and monotypic and her behaviour was bizarre and autistic-like with lack of contact and immediate and postponed echolalia. She would not initiate complicated movements like getting dressed. Neurological examination, including fundoscopy, was normal. Her IQ was estimated as $20-35$.

PATIENT 2

She was the younger sister of patient 1 who was born after an uncomplicated term pregnancy. Birth weight was $2660 \mathrm{~g}$, length $49 \mathrm{~cm}$, and OFC $34 \mathrm{~cm}$ (25th centile). She also developed postnatal macrocephaly with OFC $2 \mathrm{~cm}$ above the 97.5 th centile from the age of 6 months. Her development was delayed. She walked at the age of 24 months and exhibited the same autistic behaviour as her older sister. From the age of 5 months she started to have partial epileptic seizures with episodes of apnoea followed by drowsiness. At the age of 2 years she developed generalised complex seizures with opisthotonus, teeth grinding, frothing at the mouth, eye blinking, and myoclonic movements. The seizures were predominantly nocturnal and frequently occurred at the time of awakening or falling asleep. Interictal EEG showed generalised high voltage dysrhythmia, while ictal EEG showed a generalised 6/second spike-wave activity, predominantly in the frontal regions.

From the age of 2 she developed clinical signs of malabsorption and coeliac disease was diagnosed. ${ }^{2}$ At the age of 4 the OFC was $56 \mathrm{~cm}$ ( $2 \mathrm{~cm}>97.5$ th centile) and her height was at 

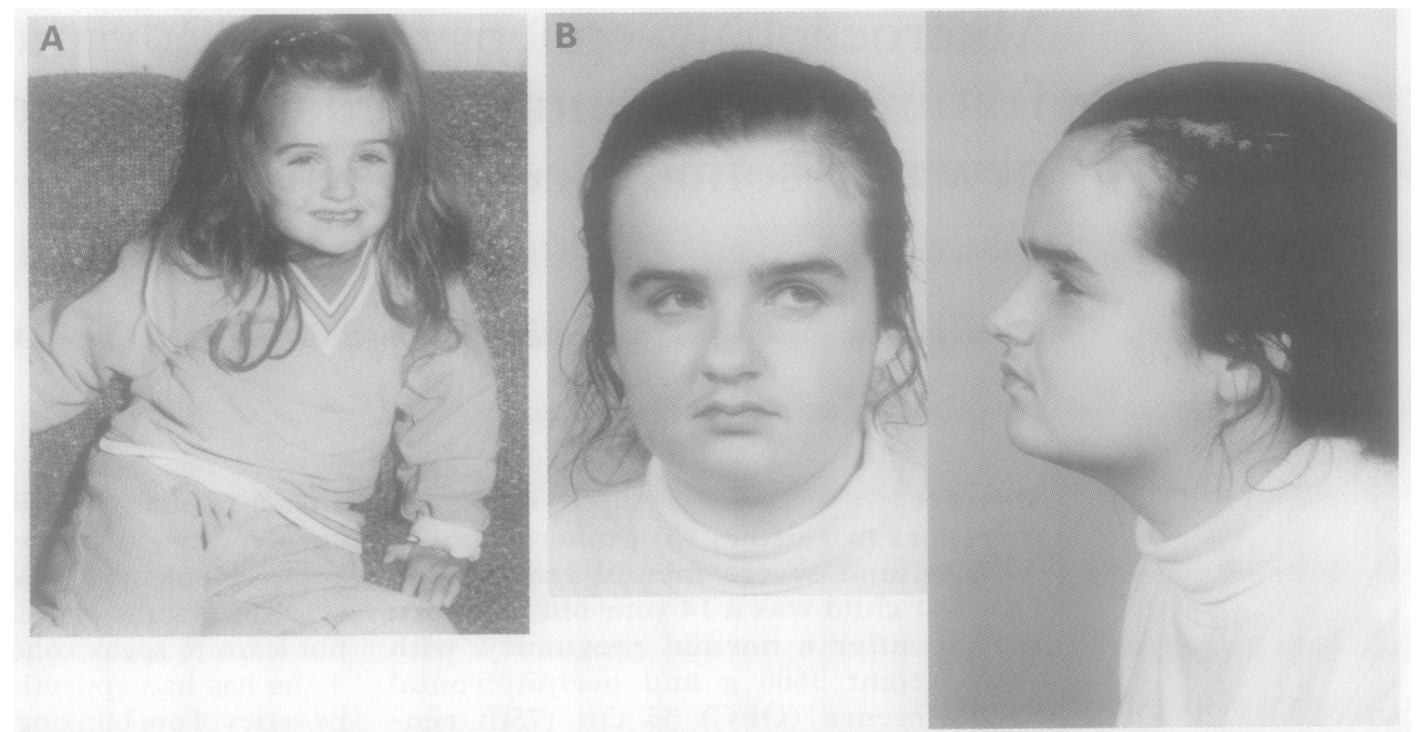

Figure 1 Patient 1 aged 5 years $(A)$ and 14 years (B). Note bushy eyebrows and blank, staring facial expression.

the 50th centile. Like her older sister she also had a prominent forehead and a short philtrum (fig 2).

She died unexpectedly at the age of 5 years, probably because of a nocturnal epileptic attack, as she had froth around her mouth when she was found dead in the morning. At necropsy all parts of the brain had normal proportions and were histologically normal. The brain weighed $1815 \mathrm{~g}$. The mean brain weight at the age of 5 is $1200 \mathrm{~g}^{3}$ and the neuropathological examination thus confirmed that the macrocephaly was the result of megalencephaly. The spinal cord and visceral organs were normal on gross and microscopic examination. The intestines were not examined histologically.

\section{FAMIILY HISTORY}

A younger sister was healthy. The parents were healthy and unrelated and of normal intelligence. The OFC of the mother was $57.5 \mathrm{~cm}$ (97th centile) and of the father $61 \mathrm{~cm}$ (97th centile). ${ }^{4}$ Their head size at birth and the postnatal rate of brain growth was unknown. There was no history of mental retardation or epilepsy in the familiy. The father had a healthy brother of normal intelligence with OFC $59 \mathrm{~cm}$ (90th centile).

\section{Supplementary investigations}

Cranial $x$ rays showed an enlarged neurocranium in all three dimensions of both patients. Otherwise the examination was unremarkable. Cerebral CT and MRI showed normal ventricular size and normal brain parenchyma, including that of the basal ganglia and cerebellum. Light and electron microscopic examination of a muscle biopsy was normal. A biopsy from the small intestine of patient 1 was also normal. Her spinal fluid had a normal protein content with normal protein electrophoresis. Urinary gas chromotography and mass spectrophotometry did not show any metabolic abnormalities. Since macrocephaly and epilepsy are features of glutaric aciduria type 1 , the activity of glutaryl-CoA-dehydrogenase in cultured fibroblasts from patient 1 was examined and found to be normal. Both sisters had a normal female karyotype. Screening for fragile $\mathrm{X}$ in $\mathbf{5 0}$ cells examined was negative.

\section{Discussion}

The main characteristics of these two sisters were early postnatal macrocephaly, epilepsy, peculiar craniofacial features, autistic behaviour, and mental retardation. The large heads of our patients could be part of a dominantly inherited benign macrocephaly unrelated to their mental and neurological dysfunction. However, the early development of pronounced macrocephaly with a high and broad forehead was more likely to be related to a brain disorder. They had no loss of abilities and the disorder therefore did not seem to be progressive. We found no biological marker suggestive of degenerative or metabolic disease

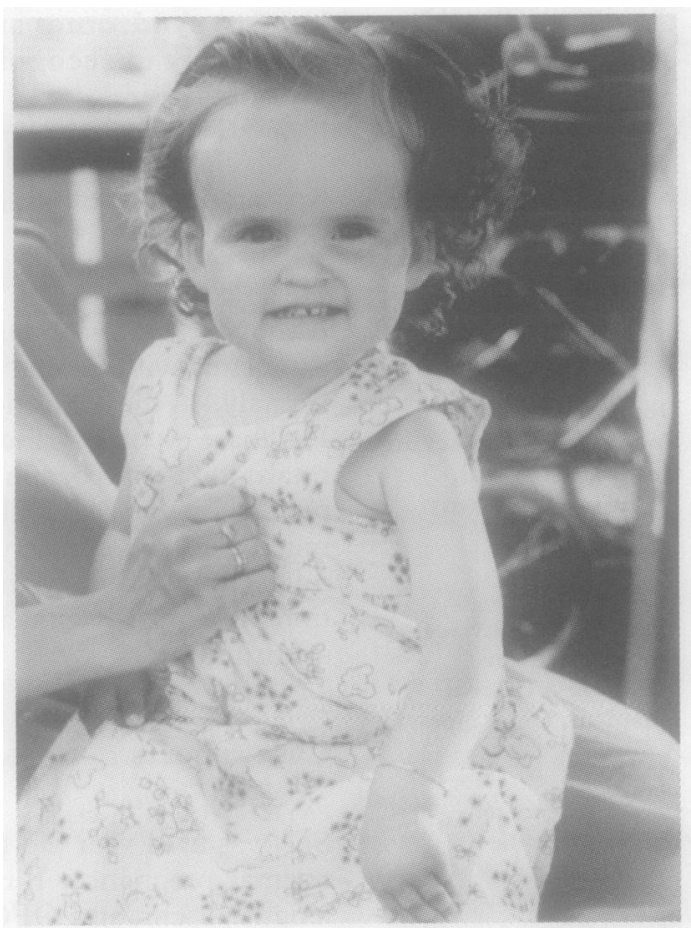

Figure 2 Patient 2 aged 2 years. Note large forehead. 
and, except for macrocephaly, the postmortem examination in patient 2 was normal. This girl probably died from an epileptic attack (SUD). ${ }^{5}$ A predisposing factor for SUD in this case may have been the tendency for epileptic ictal apnoea. ${ }^{6}$ An association between epilepsy and coeliac disease has been established. ${ }^{7}$ However, since the older sister did not have coeliac disease, it is most likely that her gluten enteropathy was not related to the neurological abnormalities.

Several sibships have been reported with a mental retardation-macrocephaly syndrome where healthy family members had large heads. Fryns et $a l^{\beta}$ reported a family with three mentally retarded macrocephalic sisters. Their mother and paternal grandfather also had large heads but normal intelligence. The authors concluded that this was probably a dominantly inherited macrocephaly-mental retardation syndrome. However, these patients had short stature and very coarse features which were different from the dysmorphic features in our patients. Cole and Hughes ${ }^{9}$ reported six probands with macrocephaly and developmental delay and a previous diagnosis of Sotos syndrome. These patients were all very similar and all of them had one parent with a large head. However, they seemed less neurologically impaired than our patients.

Sotos syndrome ${ }^{10}$ and some other macrocephaly-mental retardation syndromes include increased height and general overgrowth in infancy and childhood. Our patients were of normal height.

Buttiens $e t a^{11}$ described a possible new autosomal recessive macrocephaly-mental retardation syndrome in two sisters and a brother. The sibs had developed postnatal macrocephaly but had additional findings, including coarse facial features and ocular abnormalities with severe myopia, not present in our patients. Fryns $e t a^{12}$ reported a sister and brother who had some facial resemblance to our two sisters. These sibs also had macrocephaly with a high and broad forehead, deep set eyes, a short philtrum, and epilepsy. However, in addition they had a progressive spastic paraparesis, and they were less retarded than our patients.

In our family both parents had large heads. It cannot be excluded that the two sisters were homozygous for a gene causing borderline macrocephaly in the parents. However, this possibility seems unlikely, since both parents were of normal intelligence and their facial features did not resemble those of their offspring.

The syndrome boundaries of the reported macrocephaly-mental retardation syndromes are poorly delineated. To our knowledge the findings in these two sisters do not fit sufficiently with previously reported syndromes and may represent a new autosomal recessive mental retardation-macrocephaly syndrome.

1 Winter RM, Baraitser M. London Dysmorphology Database. Oxford: Oxford University Press, 1993.

2 Meeuwisse GW. Diagnostic criteria in coeliac disease. Acta Paediatr Scand 1970;59:461-3.

3 Coppoletta JM, Wolbach SB. Body length and organ weights of infants and children. Am $\mathcal{F}$ Pathol 1933;9:55-70.

4 Bushby KMD, Cole T, Matthews JNS, Goodship JA. Centiles for adult head circumference. Arch Dis Child 1992;67: 1286-8.

5 Leestma JE, Walczak T, Hughes J, Kalelkar MB, Teas S. A prospective study of unexpected death in epilepsy. Ann prospective study of unexp
Neurol 1989;26:195-203.

6 Nashef L, Walker F, Allen P, Sander JWAS, Shorvon SD, Fish DR. Apnoea and bradycardia during epileptic seizures: relation to sudden death in epilepsy. $₹$ Neurol Neurosurg Psychiatry 1996;60:297-300.

7 Dickey W. Epilepsy, cerebral calcifications, and coeliac disease. Lancet 1994;ii:1585-6.

8 Fryns JP, Dereymaeker AM, Haegeman J, van den Berghe H. Mental retardation, macrocephaly, short stature and
craniofacial dysmorphism in three sisters. Clin Genet 1988; 33:293-8.

9 Cole TRP, Hughes HE. Autosomal dominant macrocephaly: benign familial macrocephaly or a new syndrome? Am F Med Genet 1991;41:115-24.

10 Cole TRP, Hughes HE. Sotos syndrome: a study of the diagnostic criteria and natural history. $f$ Med Genet 1994;31:20-32.

11 Buttiens M, Fryns HP, van den Berghe $H$. An apparently new autosomal recessive syndrome with facial dysmorphism, macrocephaly, myopia and

12 Fryns JP, Hellemans $M$, van den Berghe H. Macrocephaly, distinct craniofacial appearance and spastic paraplegia: an autosomal recessive subtype of complicated spastic paraplegia. Clin Genet 1994;45:228-30. 